Article

\title{
Preparation of Silver-Plated Para-Aramid Fiber by Employing Low-Temperature Oxygen Plasma Treatment and Dopamine Functionalization
}

\author{
Zhenhua Sun ${ }^{1}$, Yanfen Zhou ${ }^{1, *}$, Wenyue Li ${ }^{1}$, Shaojuan Chen ${ }^{1}$, Shihua You ${ }^{2}$ and Jianwei Ma ${ }^{1, *}$ \\ 1 College of Textile and clothing, Qingdao University, Qingdao 266071, China; s.zhenhua@outlook.com (Z.S.); \\ WenyueLee1996@gmail.com (W.L.); qdchshj@126.com (S.C.) \\ 2 Qingdao Eros New Materials Co., Ltd., Qingdao 266108, China; keliao888@163.com \\ * Correspondence: yanfen.zhou@qdu.edu.cn (Y.Z.); mjwfz@qdu.edu.cn (J.M.)
}

Received: 9 August 2019; Accepted: 20 September 2019; Published: 23 September 2019

\begin{abstract}
Direct electroless silver plating of para-aramid (PPTA) is difficult due to its extremely low surface chemical energy. In order to facilitate the deposition of silver nanoparticles and to enhance the washing fastness, oxygen plasma treatment and dopamine modification were conducted before silver plating of PPTA fibers. Various techniques including scanning electron microscopy (SEM), attenuated total reflection Fourier transform infrared spectroscopy (ATR-FTIR), X-ray diffractometer (XRD) and thermogravimetric analyzer (TGA) were used to characterize the surface morphology, chemical composition and thermal stability of the silver-plated PPTA fibers. Electrical resistance and silver content of the silver-coated PPTA fibers before and after standard washing were also studied. The results showed that silver nanoparticles were successfully coated onto the surface of PPTA fibers with and without plasma treatment, but the coating continuity and the electrical conductivity of the silver-coated PPTA fibers were greatly enhanced with the assistance of plasma treatment. It was also demonstrated that the washing fastness of silver-coated PPTA fibers was improved after plasma treatment as indicated by electrical resistance and continuity of the silver nanoparticles after various washing cycles. It was found that the electrical resistance of plasma-treated PPTA-PDA/Ag fibers prepared at an $\mathrm{AgNO}_{3}$ concentration of $20 \mathrm{~g} / \mathrm{L}$ reached $0.89 \Omega / \mathrm{cm}$ and increased slightly to $0.94 \Omega / \mathrm{cm}$ after 10 standard washing cycles. The silver-coated PPTA fibers also showed stable electrical conductivity under 250 repeated stretching-releasing cycles at a strain of $3 \%$.
\end{abstract}

Keywords: para-aramid; oxygen plasma treatment; dopamine modification; electroless silver plating; washing fastness

\section{Introduction}

Poly ( $p$-phenylene terephthamide) (PPTA) fibers, also known as para-aramid fibers are widely used in military and aerospace industries due to their excellent physical properties, chemical and thermal stability [1,2]. Silver-plated PPTA fibers have excellent antibacterial, anti-radiation, anti-static and electromagnetic shielding properties, which greatly broadens the application of PPTA fibers, such as thermal sensing materials for smart clothing, electronic communication protection materials and multi-functional aerospace materials [3,4]. Electroless silver plating is the most widely used method to produce silver nanoparticle coated fibers [5-7]. However, as the surface reactivity of PPTA fibers is extremely low due to the displacement resistance of a large number of benzene ring formation and the conjugate effect of benzene rings and amide groups, it is difficult to obtain silver nanoparticle coated PPTA fibers by direct electroless plating.

In order to facilitate the efficient deposition of silver nanoparticles, surface modification or activation were generally required before electroless plating process $[8,9]$. Dopamine, which has strong 
adhesion to various organic/inorganic materials, has been widely used in surface modification [10,11]. It has been shown previously that dopamine modification plays an important role in the electroless plating of silver nanoparticles on fibers. For example, Wang et al. improved the electroless silver plating on the surface of silica nanofibers [12] and PET fibers [13] by dopamine modification. The results show that the obtained silver-plated fiber has low resistivity and good ultrasonic stability. The uniformity and continuity of the silver layer are excellent on the surface of the polymer materials. Liao et al. [14,15] conducted electroless silver plating on the surface of polyimide fiber with dopamine modification. The silver-coated polyimide fiber has good antibacterial activity, high conductivity and reflectivity, the electrical resistance is only $1.5 \Omega$ and the reflectivity reaches $95 \%$. In addition, there have been studies on silver-plated cotton fiber [16,17], kapok fiber [18], polyurethane fiber [19], ultrahigh molecular weight polyethylene fiber [20], polyacrylonitrile nanofibers [21], polyester fiber [22-24] and glass fiber $[24,25]$ by employing dopamine surface modification. Regarding aramid fibers, Wang et al. [26] prepared silver-plated aramid staple fiber by employing dopamine modification, which has excellent ultrasonic stability, but the staple fiber form limits the practical application of aramid, and also lacks the washing fastness test under standard conditions. Lee ${ }^{3}$ prepared silver-coated aramid fibers by using the impregnation method, the obtained fiber has good washing fastness for a duration of $30 \mathrm{~min}$, but its silver content is low and cannot form a continuous silver layer. The group of Zhang [4] successfully prepared silver-coated PPTA fibers by using traditional electroless silver plating, which has good uniformity and continuity, but the washing fastness needs to be improved. In addition, the pretreatment of traditional electroless plating involves a variety of chemical reagents, resulting in serious environmental problems. Yu's team [27] prepared silver-plated aramid filaments by using chitosan functionalization, an extremely low electrical resistance $(0.38 \Omega / \mathrm{cm})$ was achieved, but washing fastness has not been studied.

In order to further enhance the efficient deposition of silver nanoparticles and improve the coating fastness, we herein reported the low-temperature oxygen plasma treatment of PPTA fibers prior to dopamine modification. The low-temperature oxygen plasma flow contains a large number of electrons, metastable ions, and other ions. The ion flow can destroy the molecular chains on the surface of para-aramid in a short time and break chemical bonds such as amide bonds or even benzene bonds, increase the hydroxyl groups, carbonyl groups, and unsaturated bonds on para-aramid fiber surface, and hence significantly improve the surface energy and reactivity of para-aramid fiber [28]. Moreover, the damage occurs only on the surface and does not affect the mechanical properties and overall chemical structure of para-aramid fiber [29-32]. The possible reaction mechanism of low-temperature oxygen plasma treatment, dopamine functionalization, and electroless silver plating is shown in Figure 1. Plasma treatment was used to increase surface activity of PPTA fibers, resulting in more reactive sites on the fiber surface and more binding bond sites could be formed between dopamine and para-aramid [33-35]. Under aerobic conditions, the pH of dopamine solution was adjusted to 8.5 by Tris buffer, and dopamine was oxidized to an important intermediate-dopamine quinone, the molecular chains were rearranged into 5,6-dihydroxyindole (DHI) [36-38]. Finally, each product self-polymerized into polydopamine. Under the strong adhesion of polydopamine, silver-plated PPTA fibers were obtained. The bonding fastness of plated silver nanoparticles was also investigated. 


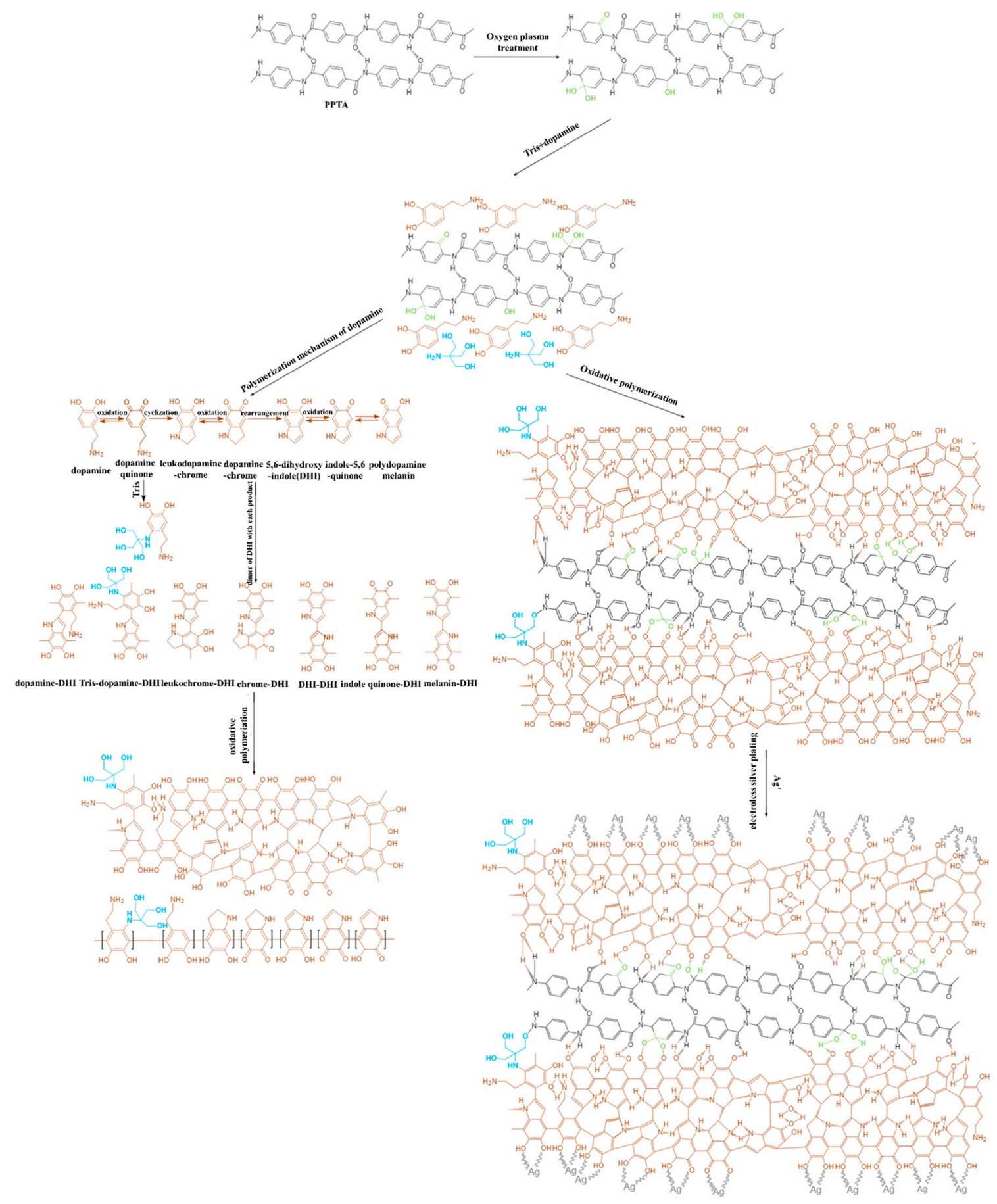

Figure 1. The possible mechanism of oxygen plasma treatment, dopamine modification and electroless silver plating $[9,10,25,33,35,38]$.

\section{Experimental}

\subsection{Materials}

The PPTA fiber bundles with a fineness of 1000 Daniel (single fiber with fineness of 1.5 Daniel, diameter of $12.5 \mu \mathrm{m}$, elongation at break of 3.4\%) were supplied by ZhongFang Special Fiber Co., Ltd., Dongying, China. Dopamine was purchased from Macklin Biochemical Co., Ltd., Shanghai, China. Trimethylol aminomethane (Tris) was purchased from Beijing Solarbio Science and Technology Co., Ltd., China. Silver nitrate $\left(\mathrm{AgNO}_{3}\right)$, Glucose, Sodium hydroxide $(\mathrm{NaOH})$, absolute ethanol and 
ammonia $\left(\mathrm{NH}_{3} \cdot \mathrm{H}_{2} \mathrm{O}\right)$ were purchased from Sinopharm Chemical Reagent Co., Ltd., Shanghai, China. All the chemicals were used as received without any further treatment.

\subsection{Preparation of Silver-Coated PPTA Fibers}

\subsubsection{Cleaning Oil on The Surface of PPTA Fibers}

The PPTA fibers were immersed in ethanol solution and ultrasonically cleaned for $30 \mathrm{~min}$ at room temperature. After cleaning, PPTA fibers were rinsed three times with deionized water and dried in a vacuum oven at $60^{\circ} \mathrm{C}$ for $2 \mathrm{~h}$.

\subsubsection{Oxygen Plasma Treatment of PPTA Fibers}

The cleaned PPTA fibers were treated with oxygen plasma by a plasma treater (AS 400, Plasmatreat $\mathrm{GmbH}$, Steinhagen, Germany). In order to make the subsequent treatment more convenient, the filament was fixed on a metal frame to prevent the fibers from entangling. The plasma treatment was conducted at a voltage of $300 \mathrm{~V}$ with various speed, jet height, oxygen flow rate, and plasma cycle time. After the oxygen plasma treatment was completed, the fibers were stored in the sample bag and the next step should be carried out as soon as possible to maximize the effect of plasma treatment.

\subsubsection{Dopamine Functionalization of PPTA Fibers}

A dopamine solution with a concentration of $2 \mathrm{~g} / \mathrm{L}$ was prepared and the $\mathrm{pH}$ of the solution was adjusted to 8.5 by adding Tris buffer. The PPTA fibers with and without plasma treatment were immersed in the dopamine solution and magnetically stirred at $25^{\circ} \mathrm{C}$ for $24 \mathrm{~h}$. After that, all samples were rinsed with deionized water three times and then dried in air for $24 \mathrm{~h}$. The pristine PPTA fibers with dopamine modification and plasma-treated PPTA fibers with dopamine modification was denoted as pristine PPTA-PDA and plasma-treated PPTA-PDA, respectively.

\subsubsection{Electroless Silver Plating on Fiber Surface}

Firstly, a silver ammonia solution was prepared as described below: The ammonia solution was added dropwise to $\mathrm{AgNO}_{3}$ solution (5-30 g/L) until the solution became clear, $\mathrm{NaOH}$ solution was dripped slowly into the ammoniacal silver nitrate solution to adjust the $\mathrm{pH}$, the ammonia solution was added slowly to the ammoniacal silver nitrate solution until the solution became clear. Then, the pristine PPTA-PDA and plasma-treated PPTA-PDA fibers were immersed in the ammoniacal silver nitrate solution for $30 \mathrm{~min}$, and the glucose solution was added to the above solution with a certain rate (about $60 \mathrm{drops} / \mathrm{min}$ ) at the temperature of $30^{\circ} \mathrm{C}$. The reaction was allowed to proceed at room temperature for several hours. The silver-plated PPTA fibers were rinsed with deionized water three times and dried in a vacuum oven at $60^{\circ} \mathrm{C}$ for $2 \mathrm{~h}$. The overall process to obtain silver-plated PPTA fibers is shown schematically in Figure 2.

\subsection{Washing Fastness Test of Silver-Plated PPTA Fiber Bundles}

Washing fastness of the prepared silver-plated PPTA fibers was tested by using a textile-color fastness meter (SW-20B, Quanzhou MeiBang Instrument Co., Ltd., Quanzhou, China). The washing process was conducted according to Chinese standard GB/T 3921-2008 [39]. Specifically, the samples were washed at $40^{\circ} \mathrm{C}$ for 10 cycles (30 min/cycle) with a bath radio of 50:1 and a rotating speed of $40 \pm$ $2 \mathrm{r} / \mathrm{min}$. After each washing was completed, the samples were dried in a vacuum oven at $60^{\circ} \mathrm{C}$ for $2 \mathrm{~h}$.

\subsection{Tensile Strain Test of Silver-Plated PPTA Fiber Bundles}

Silver-plated PPTA fiber bundles with a length of $20 \mathrm{~mm}$ were subjected to repeated stretching-releasing tests at a constant strain 3\%. The real-time change of electrical resistance with tensile strain was measured by using a precision source/measure unit (B2901A, Keysight, Santa Rosa, CA, USA). 


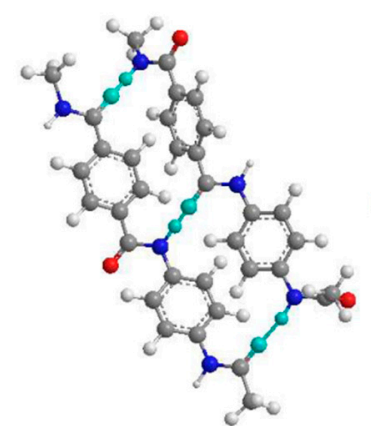

Oxygen Plasma Treatment

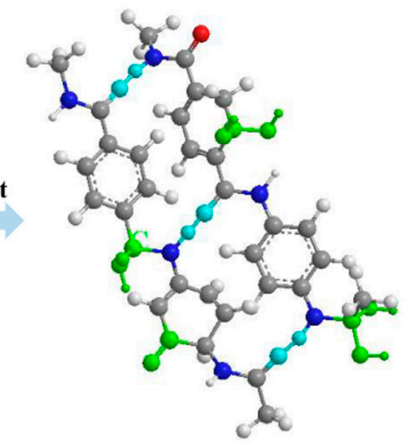

PPTA

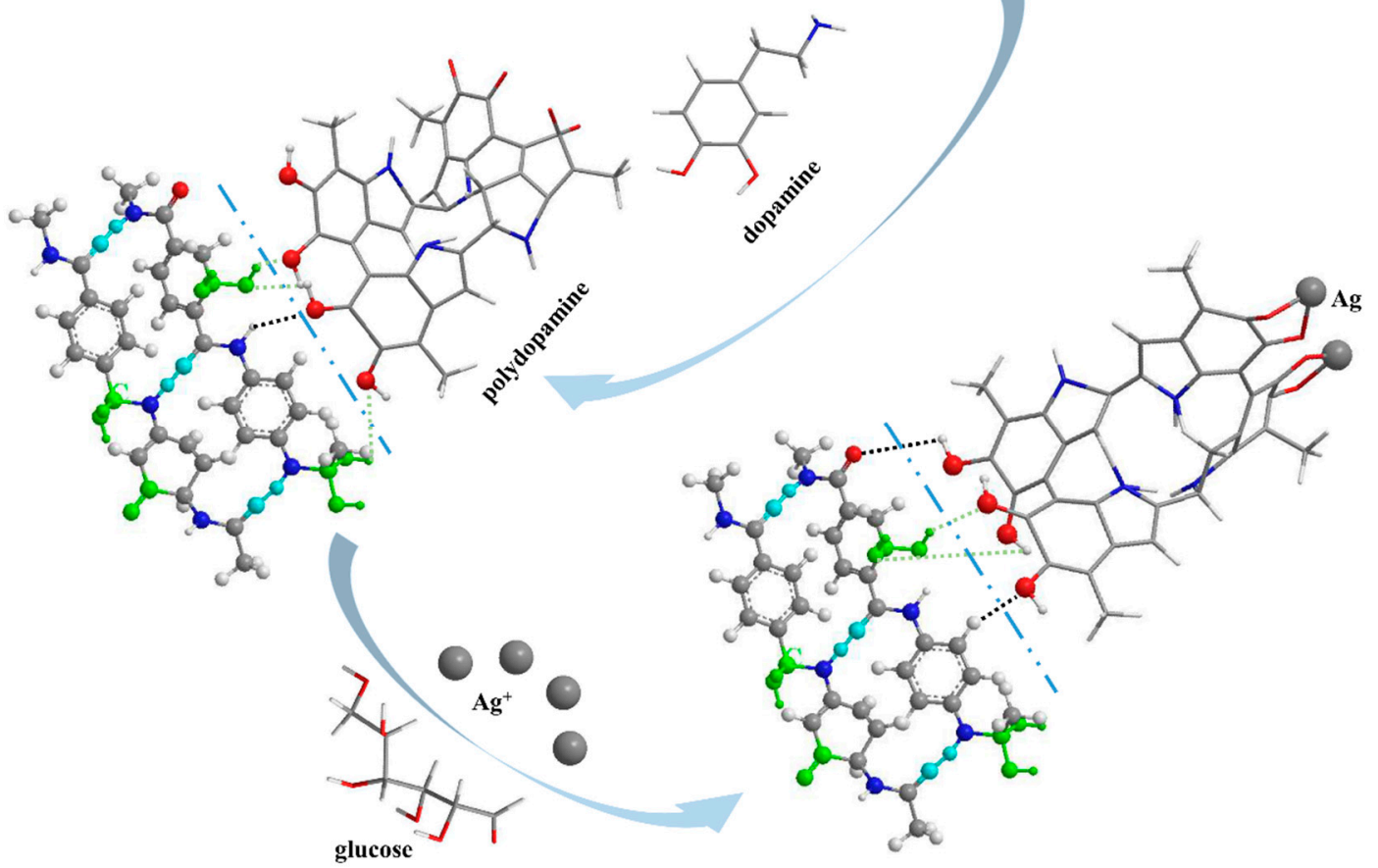

Figure 2. Schematic illustration of the process to obtain silver-plated Poly ( $p$-phenylene terephthamide) (PPTA) fibers.

\subsection{Characterization}

The surface morphology of pristine PPTA fibers, plasma-treated PPTA fibers, dopamine treated PPTA fibers, and silver-coated PPTA fibers were observed by using a scanning electron microscopy (SEM) (VEGA3, TESCAN, Brno, Czech) which is equipped with an energy dispersive spectrometer (EDS). The samples were mounted on the test bench by a conductive adhesive and sputtered with a thin layer of platinum on the surface. SEM images with a magnification of $10 \mathrm{k} \times$ were taken at a voltage of $10 \mathrm{kV}$.

The particle size of silver particles was counted by using Image J software. The size of 100 silver particles was measured and the average value of particle size was used.

The attenuated total reflection Fourier transform infrared spectroscopy (ATR-FTIR) of pristine PPTA fibers, pristine PPTA-PDA fibers, plasma-treated PPTA fibers, and plasma-treated PPTA-PDA fibers was studied by NICOLET iN10MX (Thermo Fisher Scientific, Waltham, MA, USA). After selecting the ATR module of the spectrometer and focusing the sample, the detector was installed to collect the infrared spectrum data of the sample at a resolution of $16 \mathrm{~cm}^{-1}$ and a wavelength range of $4000 \sim 675 \mathrm{~cm}^{-1}$.

The crystalline structure of the samples was detected by X-ray diffraction (XRD, Rigaku Ultima IV, Tokyo, Japan). X-ray diffraction patterns of each sample were obtained in a reflection mode in the $2 \theta$ range of $5^{\circ}-90^{\circ}$, the step was $0.02^{\circ}$ and the scanning speed was $5^{\circ} / \mathrm{min}$. 
Thermo stability of the samples was performed by using a thermogravimetric analyzer (STA 449 F3, NETZSCH GmbH, Selb, Germany). The fiber samples were conditioned for $24 \mathrm{~h}$ under standard atmospheric conditions $\left(20^{\circ} \mathrm{C} / 65 \%\right)$. Each sample was weighed $5 \sim 10 \mathrm{mg}$ separately into the burned crucible and the weight loss curve of the samples was obtained by raising to $800{ }^{\circ} \mathrm{C}$ at a heating rate of $20{ }^{\circ} \mathrm{C} / \mathrm{min}$.

The electrical resistance of the samples was measured using a precision source/measure unit. Thirty different positions were selected for each sample and the average values were used.

\section{Results and Discussion}

\subsection{Oxygen Plasma Treatment and Dopamine Functionalization}

The surface morphology of pristine PPTA fibers and plasma-treated PPTA fibers was observed by using SEM. Figure 3 shows the SEM images of the pristine PPTA fibers (Figure 3a) and plasma-treated PPTA fibers (Figure 3b). It can be seen that the pristine PPTA fibers had a smooth surface without impurities while the surface of plasma-treated PPTA fibers was etched to a certain extent, the roughness, as well as the specific surface area, were improved, which provided more favorable conditions for the deposition of dopamine. Figure 3c,d shows the SEM images of pristine PPTA-PDA fibers and plasma-treated PPTA-PDA fibers, respectively. It was found that the deposition of polydopamine on plasma-treated PPTA fibers was more evident than the pristine PPTA fibers. This was because plasma treatment roughened the surface of the fiber and increased surface reactivity.

Energy dispersive spectrometer was used to investigate the element types and contents of PPTA fibers. Figure 3 shows the energy spectrum of PPTA fibers before $\left(a^{\prime}\right)$ and after $\left(b^{\prime}\right)$ oxygen plasma treatment. It can be seen that pristine PPTA fibers were composed of $\mathrm{C}, \mathrm{H}$, and $\mathrm{O}$ with a nitrogen to oxygen ratio $(\mathrm{N} / \mathrm{O})$ of 0.874 , which was close to the theoretical of 0.875 . After plasma treatment, the element type of PPTA fibers did not change but the element content changed, especially the oxygen element indicating that oxygen plasma treatment was successful. The element content of pristine PPTA fibers (Figure 3c') and plasma-treated PPTA fibers (Figure 3d') after dopamine modification was varied, with a nitrogen to carbon ratio $(\mathrm{N} / \mathrm{C})$ of 0.118 and 0.120 respectively, which was similar to the dopamine theoretical value of 0.125 suggesting that polydopamine was successfully deposited on the PPTA surface.

ATR-FTIR was used to study the changes in functional groups in PPTA fibers after different treatments, and the results are shown in Figure 4 The absorption peak at $3313 \mathrm{~cm}^{-1}$ was the stretching vibration of $\mathrm{N}-\mathrm{H}$ in PPTA. There was a large number of absorption peaks in the range of $1650 \sim 700 \mathrm{~cm}^{-1}$, including $\mathrm{C}=\mathrm{O}$ stretching vibration at $1639 \mathrm{~cm}^{-1}$ (amide I band), $\mathrm{N}-\mathrm{H}$ bending vibration at $1538 \mathrm{~cm}^{-1}$, $\mathrm{N}-\mathrm{H}$ plane bending vibration at $1515 \mathrm{~cm}^{-1}$ (amide II band), $-\mathrm{CH}_{2}$ - stretching vibration in the $\mathrm{C}-\mathrm{H}$ plane at $1400 \mathrm{~cm}^{-1}, \mathrm{C}-\mathrm{N}$ stretching vibration at $1311 \mathrm{~cm}^{-1},-\mathrm{OH}$ stretching vibration at 1257,1110 and $1018 \mathrm{~cm}^{-1},=\mathrm{C}-\mathrm{H}$ bending vibration at $894 \mathrm{~cm}^{-1}$, benzene ring stretching vibration at 864 and $821 \mathrm{~cm}^{-1}$, cooperative vibration of methylene segment $\left(\mathrm{CH}_{2}\right)_{n}(n>4)$ at $725 \mathrm{~cm}^{-1}$. All absorption peaks described above were related to PPTA fibers. There was no change in the functional groups after plasma treatment. It can be seen from Figure $4 \mathrm{~b}$, d that the dopamine-treated PPTA exhibits a weak absorption peak at $1357 \mathrm{~cm}^{-1}$, which was ascribed to the stretching vibration of unique indole group $(\mathrm{C}-\mathrm{N}-\mathrm{C})$ in polydopamine. In addition, polydopamine also had $\mathrm{C}=\mathrm{C}$ resonance vibration at $1615 \mathrm{~cm}^{-1}$, $\mathrm{N}-\mathrm{H}$ bending vibration at $1520 \mathrm{~cm}^{-1}$ and $\mathrm{C}-\mathrm{N}$ stretching vibration at $1437 \mathrm{~cm}^{-1}$, but this was not unique to polydopamine. PPTA fibers also had absorption peaks at these positions, so the absorption peak of polydopamine at these positions was overlapped [40]. Therefore, it is concluded that plasma treatment has no effect on the chemical structure of PPTA fibers, the modification of PPTA fibers by using dopamine is successful. 

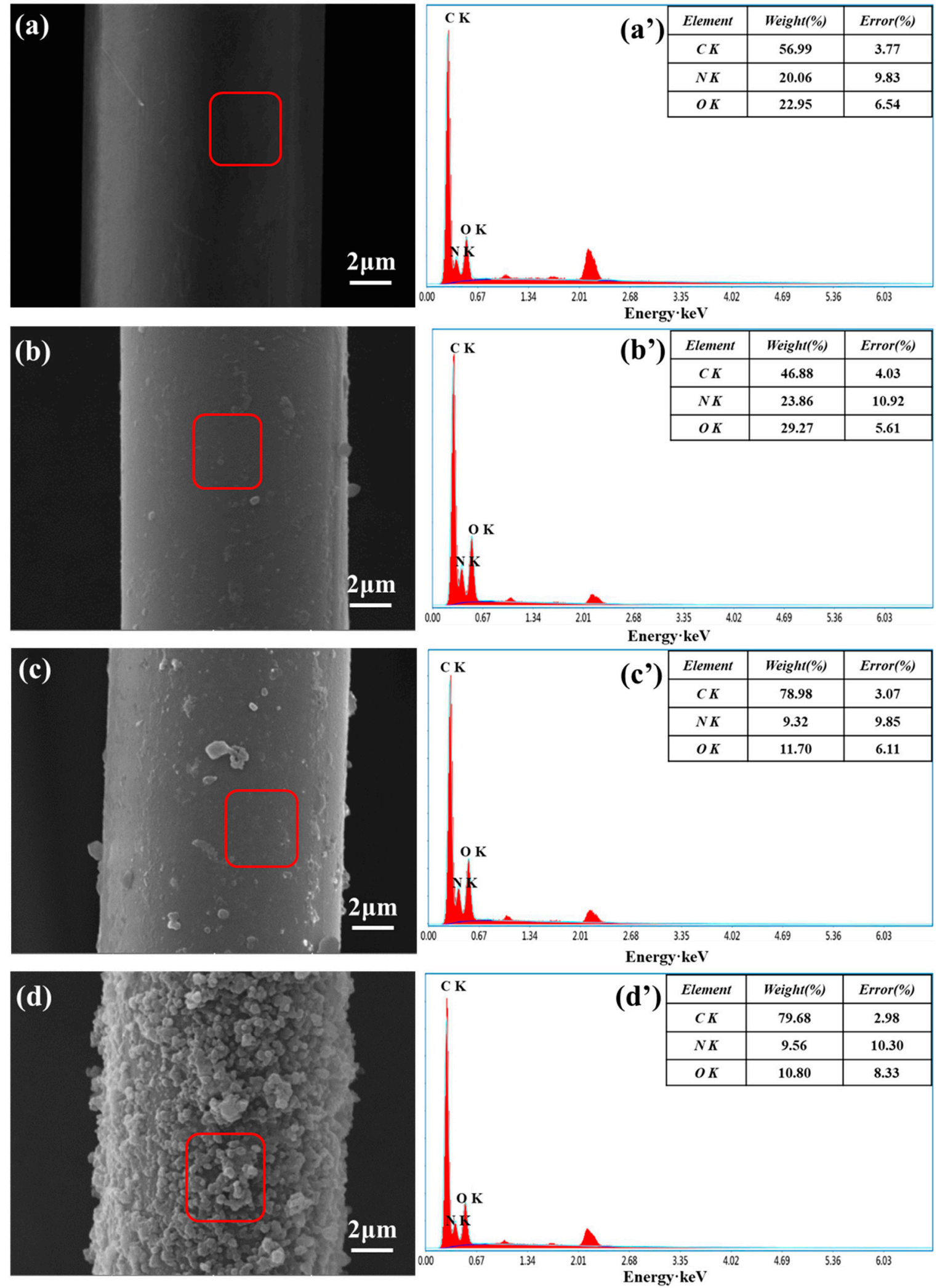

Figure 3. SEM images of (a) pristine PPTA fibers, (b) plasma-treated PPTA fibers, (c) pristine PPTA-PDA fibers and (d) plasma-treated PPTA-PDA fibers. Energy spectrum of $\left(\mathbf{a}^{\prime}\right)$ pristine PPTA fibers, $\left(\mathbf{b}^{\prime}\right)$ plasma-treated PPTA fibers, $\left(\mathbf{c}^{\prime}\right)$ pristine PPTA-PDA fibers and $\left(\mathbf{d}^{\prime}\right)$ plasma-treated PPTA-PDA fibers. 


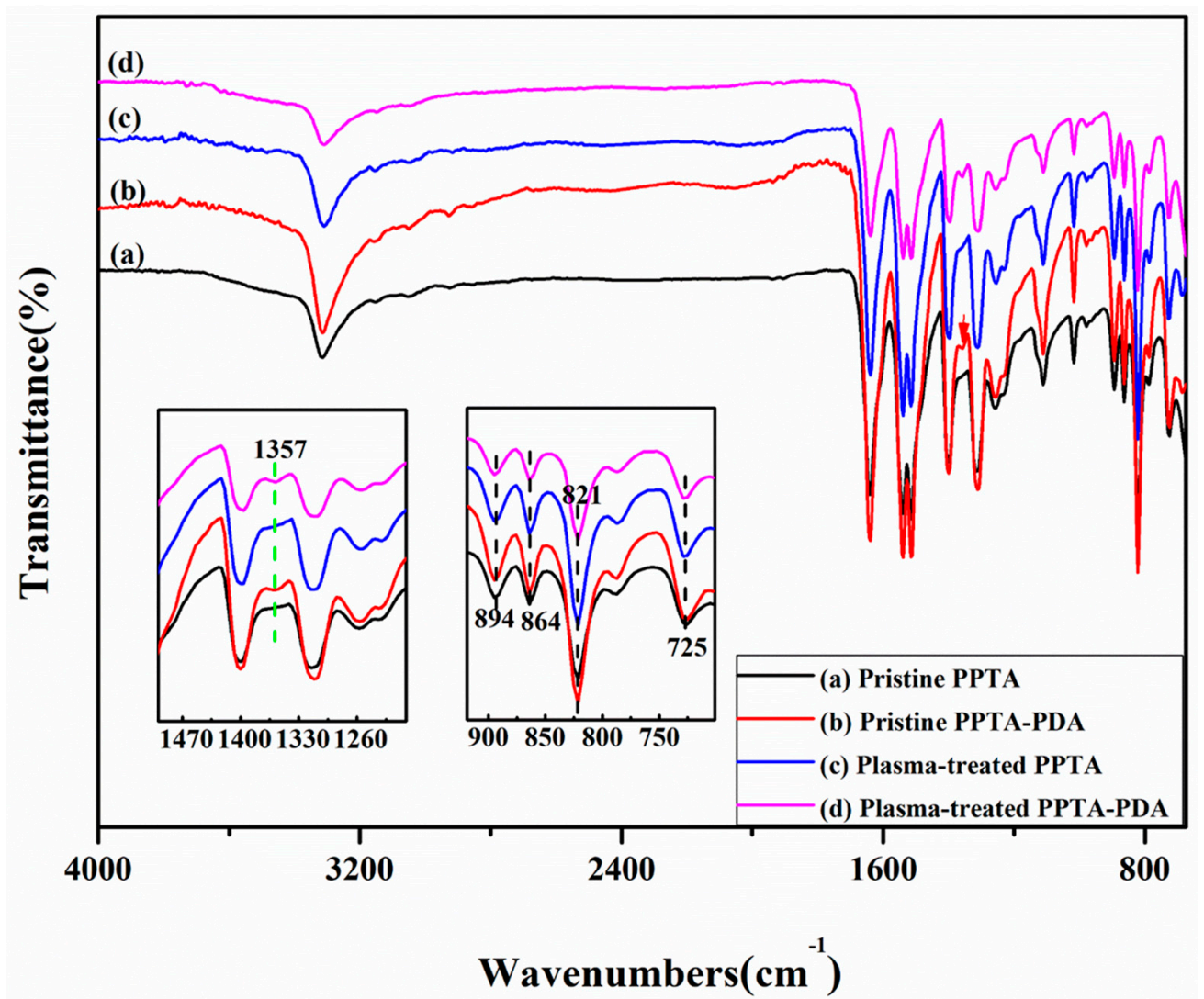

Figure 4. The attenuated total reflection Fourier transform infrared spectroscopy of (a) pristine PPTA fibers, (b) pristine PPTA-PDA fibers, (c) plasma-treated PPTA fibers and (d) plasma-treated PPTA-PDA fibers.

\subsection{Electroless Silver Plating on PPTA Fiber Surface}

The deposition of silver nanoparticles on the PPTA surface was confirmed by using X-ray diffraction. Figure 5 shows the X-ray diffraction patterns of pristine PPTA fibers, plasma-treated PPTA fibers, plasma-treated PPTA-PDA fibers, pristine PPTA-PDA/Ag fibers and plasma-treated PPTA-PDA/Ag fibers. It can be seen that the pristine PPTA fibers had diffraction peaks at the $2 \theta$ values of $20.9^{\circ}$ and $23.0^{\circ}$, indicating that the pristine PPTA fibers contain a partially crystalline structure $[26,27]$. The diffraction peak at the $2 \theta$ value of $28.5^{\circ}$ appearing in plasma-treated PPTA fibers and plasma-treated PPTA-PDA fibers suggests that plasma treatment affects the crystal structure of PPTA fibers. A large number of studies have shown that plasma treatment affected the microcrystalline structure of aramid fiber, but it showed very little damage in macroscopic mechanical properties [29,32,41-43]. Comparing Figure $5 b, c$, it can be concluded that dopamine modification had no effect on the crystal structure of PPTA fibers. Figure $5 d$,e shows five distinct diffraction peaks at the $2 \theta$ values of $38.4^{\circ}, 44.6^{\circ}, 64.8^{\circ}$, 77.6 $6^{\circ}$, and 81.8 , corresponding to the (1 11 1), (2 00 ), (2 20 ), (3 11 1), and (2 2 2) planes of face-centered cubic lattice (FCC) phase silver (JCPDS card), respectively. In Figure 5d,e, only the characteristic peaks of PPTA fibers and silver were shown and no diffraction peaks of silver oxides and compounds appeared, indicating that the silver was successfully plated onto the fiber surface and the silver was in elemental form.

Thermogravimetric analysis was used to understand the thermal stability of the materials. Figure 6 shows the thermal decomposition curve of PPTA fibers at various stages of the process. It can be seen from Figure 6 that the moisture content of the pristine PPTA fibers and plasma-treated PPTA fibers was $2.87 \%$ and $0.61 \%$, respectively. As the moisture regain of PPTA fibers was closely related to the degree of crystallinity, the difference in moisture content confirmed that the crystallization of PPTA fiber had changed, which was in accordance with the XRD results. As can be seen, the decomposition 
temperature of the pristine PPTA fibers and plasma-treated PPTA fibers, dopamine-modified PPTA fibers and silver-plated PPTA fibers ranged from 568.3 to $595^{\circ} \mathrm{C}$, indicating that these treatments did not affect the thermal stability of PPTA fibers.

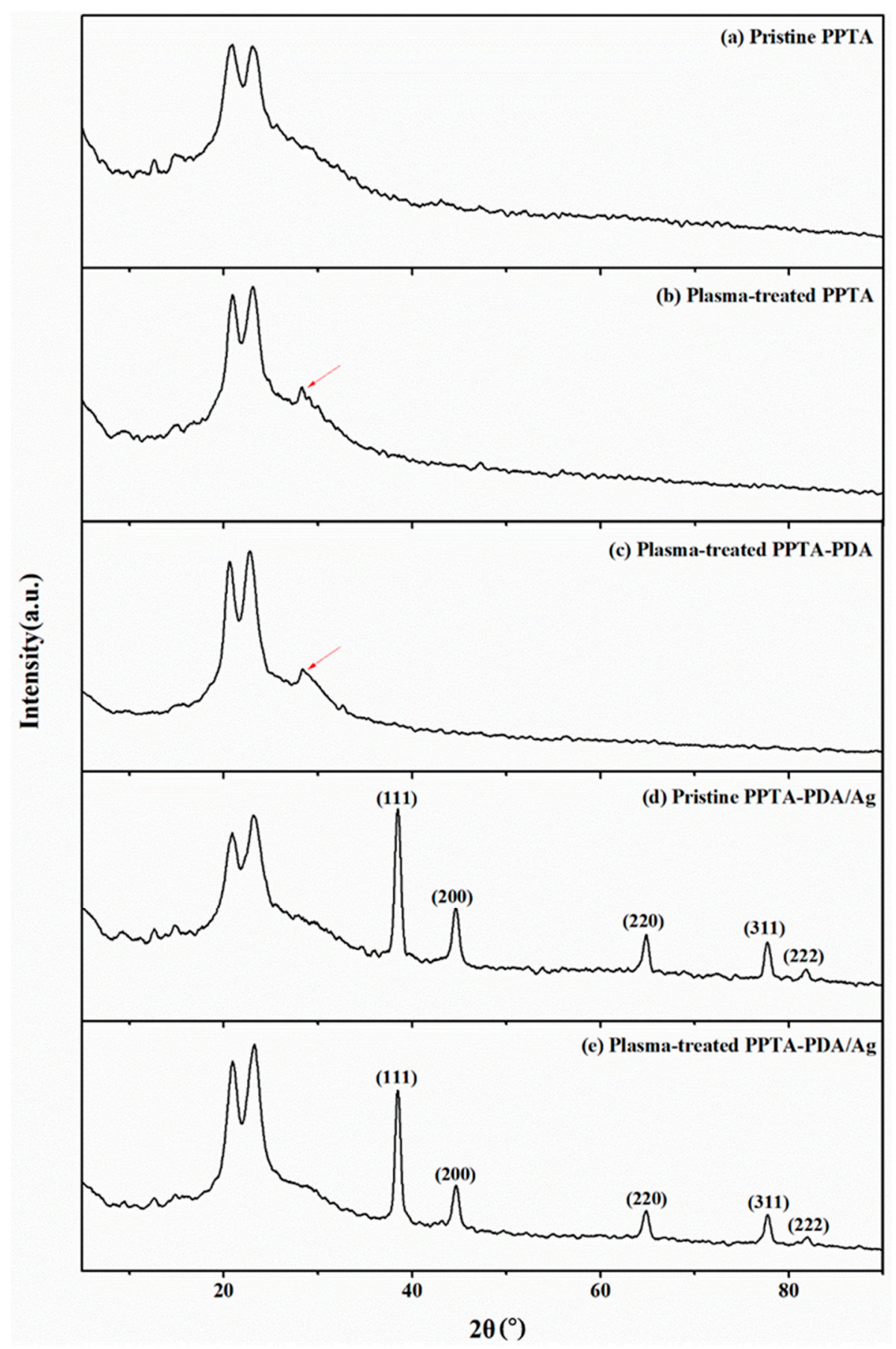

Figure 5. X-ray diffraction patterns of (a) pristine PPTA fibers, (b) plasma-treated PPTA fibers, (c) plasma-treated PPTA-PDA fibers, (d) pristine PPTA-PDA/Ag fibers and (e) plasma-treated PPTA-PDA/Ag fibers.

The surface morphology of silver-plated PPTA fibers and silver-plated PPTA fibers after washing was observed by using SEM. Figure 7 shows the SEM images of pristine PPTA-PDA/Ag fibers and plasma-treated PPTA-PDA/Ag fibers before and after 10 washing cycles. It can be seen that the surface of pristine PPTA-PDA/Ag fibers without washing had good continuity and uniformity. However, with 
the increase of washing time, the silver layer of pristine PPTA-PDA/Ag fibers was gradually destroyed, the uniformity of the silver layer was seriously damaged after 10 washing cycles and there were many discontinuities in the silver layer. Whereas in contrast, the formed silver layer on plasma-treated PPTA-PDA/Ag fibers was slightly affected by washing, the silver layer still maintained good uniformity and continuity after 10 washing cycles, as can be seen from Figure $7 \mathrm{~d}$. This further confirmed that plasma treatment was not only beneficial to the deposition of silver nanoparticles on the PPTA surface but also to the fastness of the deposited silver nanoparticles.

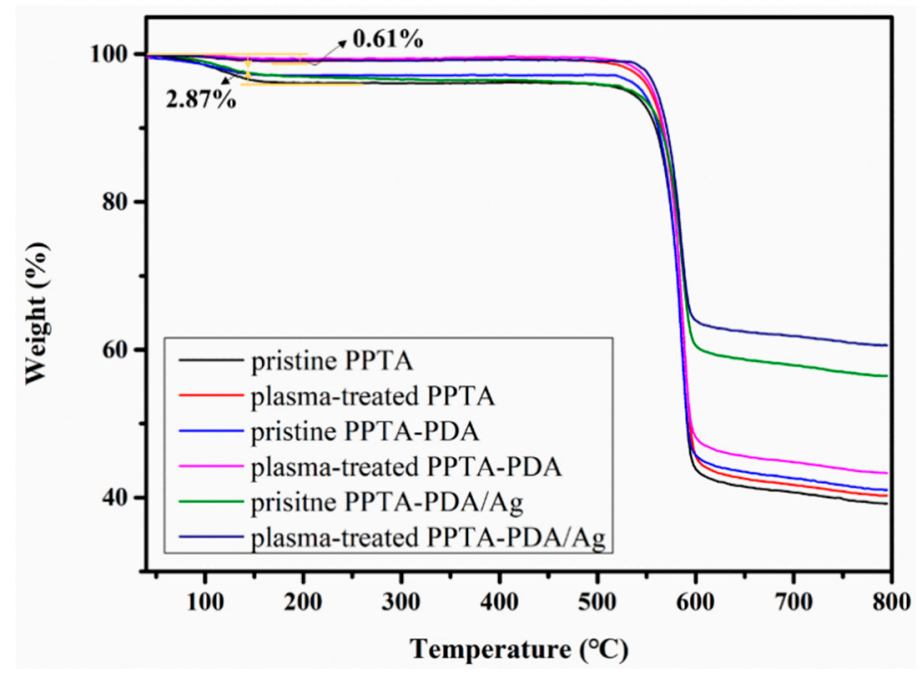

Figure 6. Thermogravimetric analysis of pristine PPTA fibers, plasma-treated PPTA fibers, dopamine functionalized PPTA fibers and silver-coated PPTA fibers $\left(\mathrm{AgNO}_{3}\right.$ concentration was $\left.20 \mathrm{~g} / \mathrm{L}\right)$.
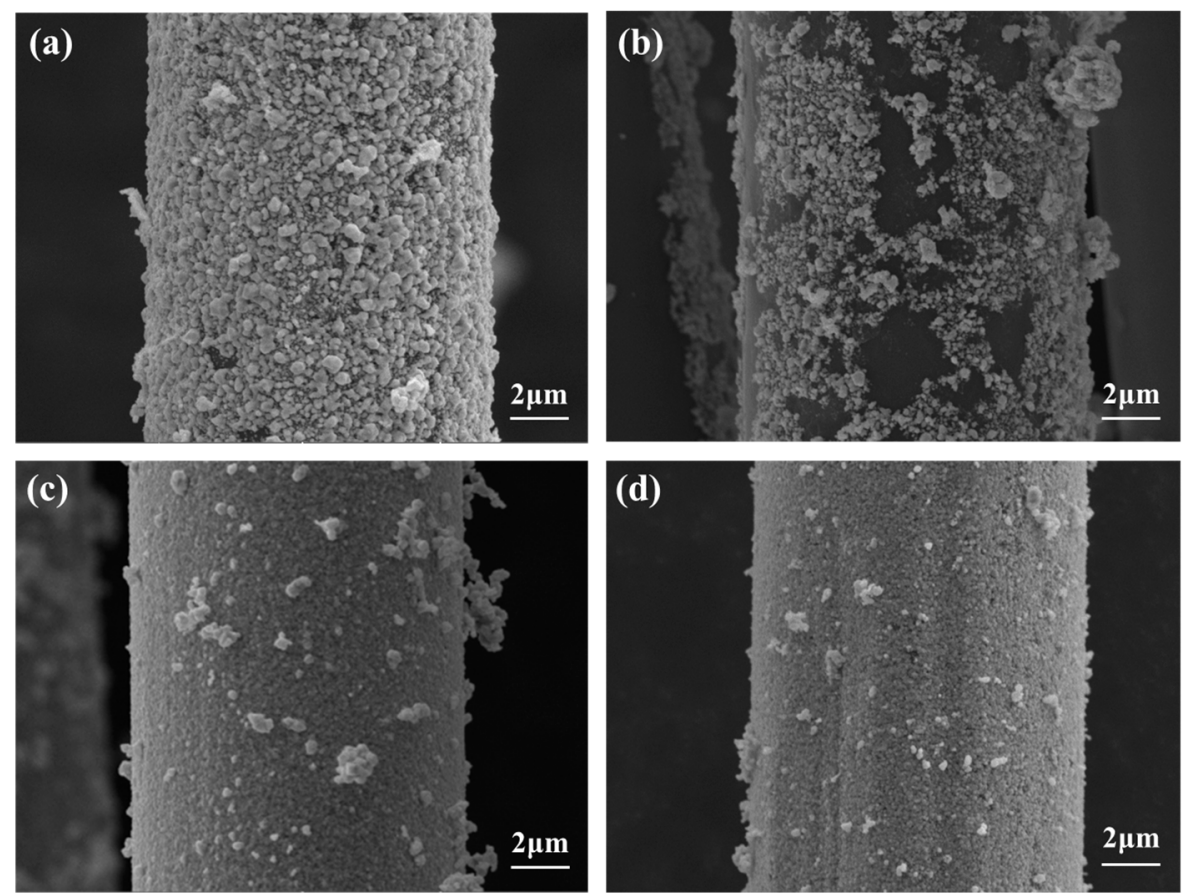

Figure 7. The SEM images of pristine PPTA-PDA/Ag fibers before (a) and after (b) 10 washing cycles, plasma-treated PPA-PDA/Ag fibers before (c) and after (d) 10 washing cycles. The $\mathrm{AgNO}_{3}$ concentration was $20 \mathrm{~g} / \mathrm{L}$.

The electrical resistance and silver content of silver-plated fiber can quantitatively reflect uniformity and continuity of the silver coating. Figure 8 shows the change of electrical resistance and silver 
content of silver-plated PPTA fibers after different washing time. It can be seen from Figure $8 \mathrm{a}$ that the electrical resistance of both pristine PPTA-PDA/Ag fibers and plasma-treated PPTA-PDA/Ag fibers increased with washing time. The electrical resistance of pristine PPTA-PDA/Ag fibers increased obviously while that of plasma-treated PPTA-PDA/Ag fibers increased slightly. A similar conclusion can be obtained from Figure $8 \mathrm{~b}$ that the silver content of silver-plated fiber with and without plasma treatment at different washing time decreased in varying degrees. However, the silver content of pristine PPTA-PDA/Ag fibers decreased significantly while that of plasma-treated PPTA-PDA/Ag fibers decreased slightly. The electrical resistance and silver content of plasma-treated PPTA-PDA/Ag fibers after 10 washing cycles (300 $\mathrm{min}$ ) was $0.94 \Omega / \mathrm{cm}$ and $14.09 \%$ respectively, while that of pristine PPTA-PDA/Ag fibers was $16.88 \Omega / \mathrm{cm}$ and $7.21 \%$ respectively. This quantitively confirmed that plasma treatment significantly improved the silver plating and bonding fastness of silver nanoparticles.
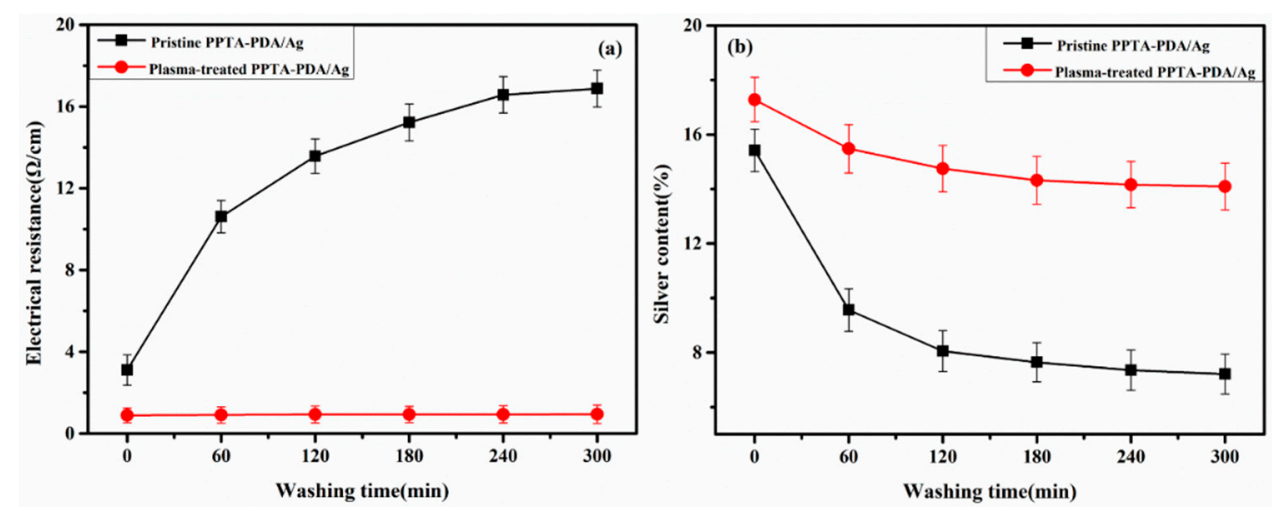

Figure 8. The variation of electrical resistance (a) and silver content (b) of pristine PPTA-PDA/Ag fibers and plasma-treated PPTA-PDA/Ag fibers with washing time. The $\mathrm{AgNO}_{3}$ concentration was $20 \mathrm{~g} / \mathrm{L}$.

In order to explain the difference in the bonding fastness of silver nanoparticles, a model describing the deposition state of silver nanoparticles on the PPTA surface was established, as shown in Figure 9. Assuming the silver nanoparticles are spherical, the pore volume occupied by a single silver particle was estimated according to the following formula:

$$
V=(1-\pi / 6) a^{3}
$$

where $\mathrm{a}$ is the particle diameter. The pore volume formed by eight particles was the same as the pore volume occupied by a single particle, so when the silver nanoparticle diameter was in nanoscale, the average pore volume between silver nanoparticles in the silver layer was about $0.48 a^{3} \mathrm{~nm}^{3}(\pi \approx 3.14)$. When the silver-plated PPTA fibers were washed with water, the pore volume of the silver layer was larger and more water molecules were contacted with the silver nanoparticles, and the damage of silver layer was more serious. Figure 10 shows the particle size distribution of silver nanoparticles of pristine PPTA-PDA/Ag fibers and plasma-treated PPTA-PDA/Ag fibers. The particle size of pristine PPTA-PDA/Ag fibers and plasma-treated PPTA-PDA/Ag fibers was $193 \pm 20$ and $130 \pm 13 \mathrm{~nm}$, respectively. The particle size of plasma-treated PPTA-PDA/Ag fibers was 32.6\% lower than pristine PPTA-PDA/Ag fibers. The average pore volume of the silver layer of pristine PPTA-PDA/Ag fibers and plasma-treated PPTA-PDA/Ag fibers was $3.45 \times 10^{6}$ and $1.05 \times 10^{6} \mathrm{~nm}^{3}$, respectively. Therefore, it was thought that the improvement in the bonding fastness of plasma-treated PPTA-PDA/Ag fibers was related with the reduced particle size of silver nanoparticles and the pore volume. 

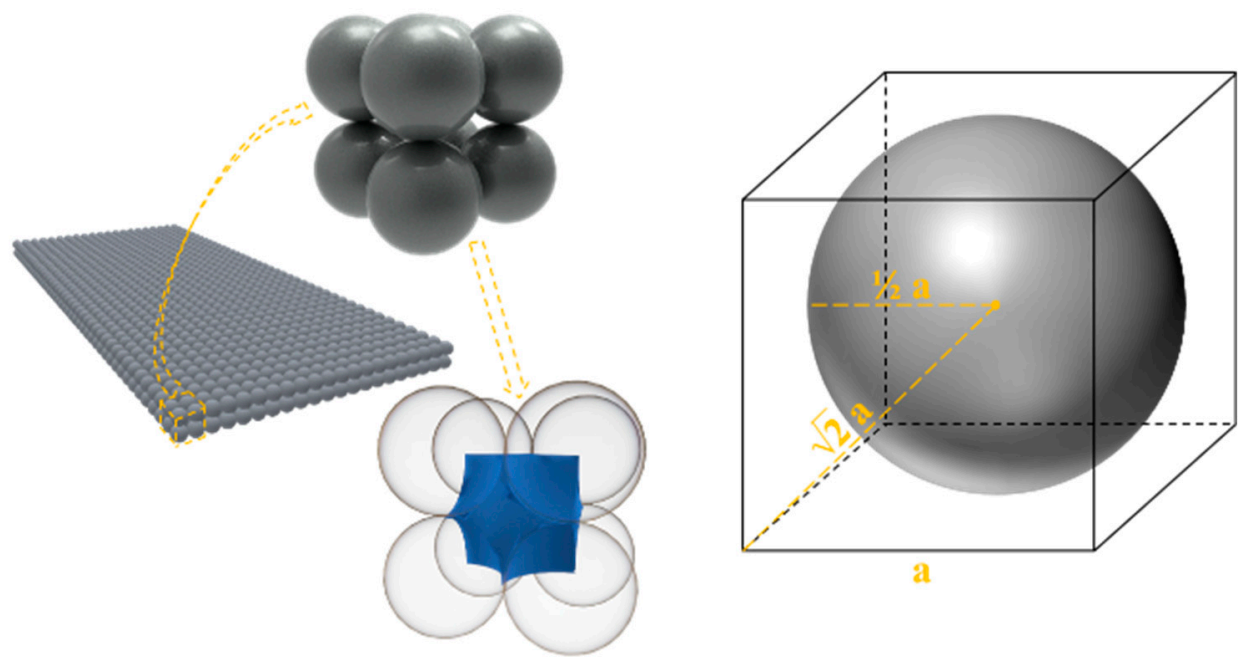

Figure 9. The theoretical model of regular arrangement of silver nanoparticles, the nanoparticle with a diameter of a nm and pore model established (assuming the silver nanoparticles are spherical).
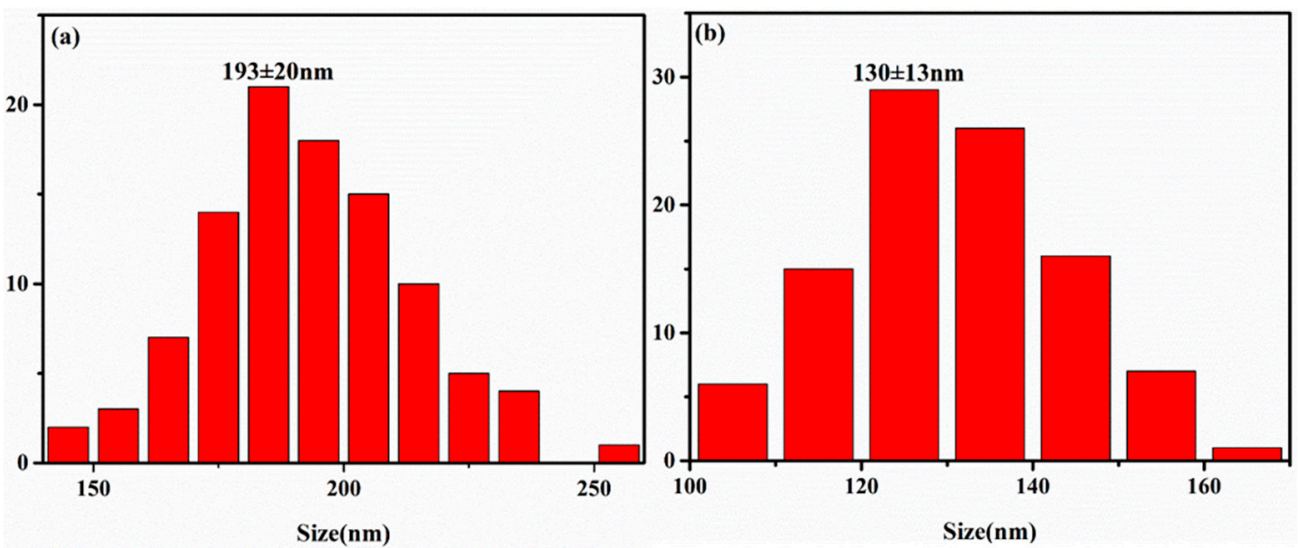

Figure 10. Particle size distribution of pristine PPTA-PDA/Ag fibers (a) and plasma-treated PPTA-PDA/Ag fibers (b).

SEM images of plasma-treated PPTA-PDA/Ag fibers prepared at different $\mathrm{AgNO}_{3}$ concentrations before and after washing are shown in Figures 11 and 12 shows the effect of $\mathrm{AgNO}_{3}$ concentration on the electrical resistance and silver content of plasma-treated PPTA-PDA/Ag fibers before and after standard washing. It can be seen from Figure 12a that the electrical resistance of plasma-treated PPTA-PDA/Ag fibers decreased and the silver content increased with the increase of $\mathrm{AgNO}_{3}$ concentration. The electrical resistance was reduced to $0.89 \Omega / \mathrm{cm}$ and basically stabilized and the coating was uniform and continuous when the $\mathrm{AgNO}_{3}$ concentration reached $20 \mathrm{~g} / \mathrm{L}$ (Figure 11d). With further increase in $\mathrm{AgNO}_{3}$ concentration, agglomeration of silver nanoparticles appeared on the surface of PPTA fibers, and the uniformity of coating was greatly affected (Figure 10f). It can be seen from Figure $12 \mathrm{~b}$ that as the $\mathrm{AgNO}_{3}$ concentration increased, the electrical resistance of silver-coated PPTA fibers after washing decreased to a minimum $(0.94 \Omega / \mathrm{cm})$ and then increased slightly, while the silver content reached a maximum (14.09\%) and then decreased gradually. The agglomeration of silver nanoparticles resulted in a decrease in coating flexibility and the buffer capacity of coating for water flow was weakened. It was seen clearly from Figure $11 \mathrm{~g}-1$ that plasma-treated PPTA-PDA/Ag fibers prepared at $\mathrm{AgNO}_{3}$ concentration of $20 \mathrm{~g} / \mathrm{L}$ (Figure 11j) had the best washing fastness. This suggested that $20 \mathrm{~g} / \mathrm{L}$ was the most reasonable $\mathrm{AgNO}_{3}$ concentration to obtain silver-plated PPTA fibers with uniform and compact surface morphology, as well as a reliable coating fastness. 

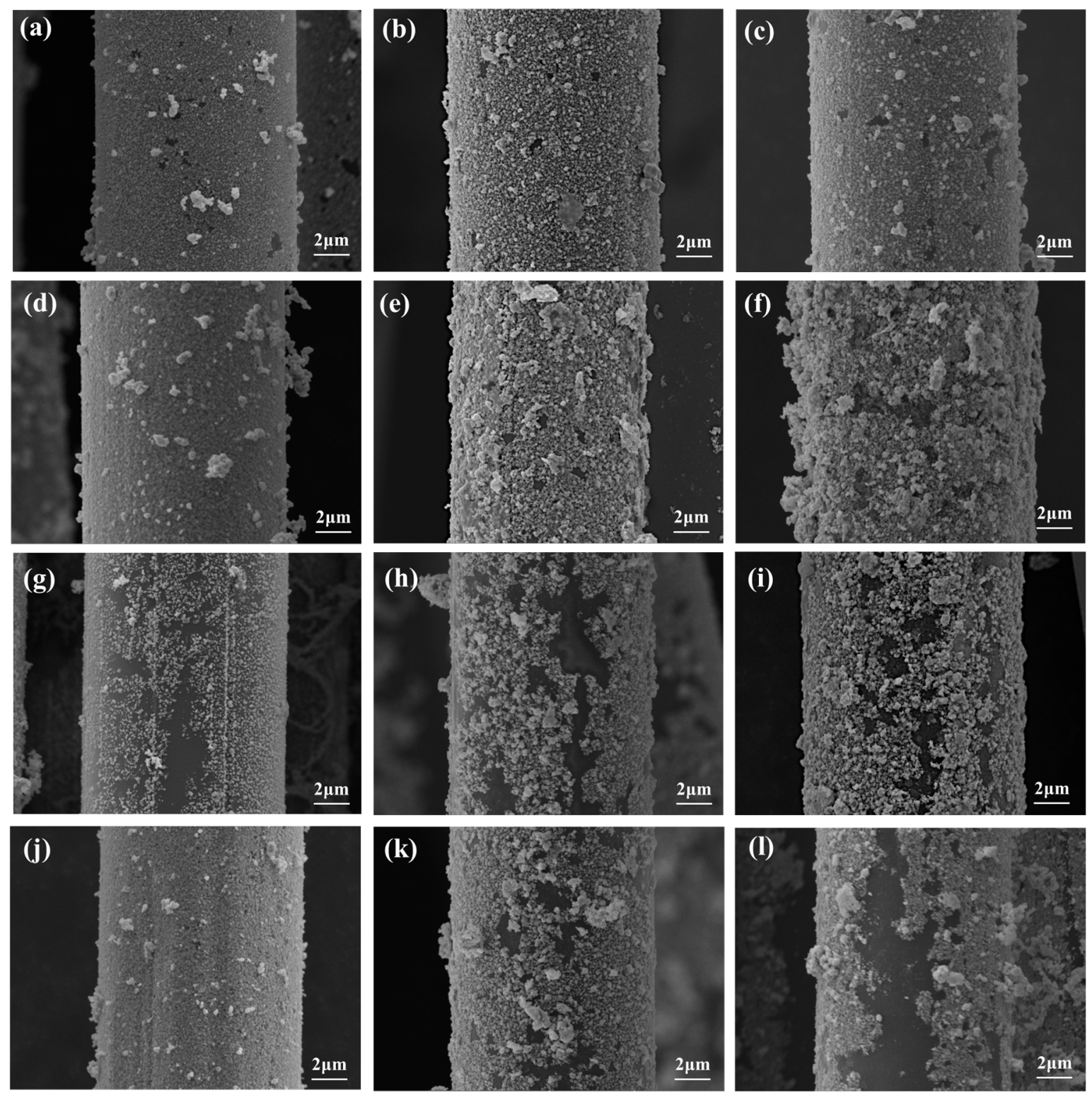

Figure 11. SEM images of plasma-treated PPTA-PDA/Ag fibers prepared at $\mathrm{AgNO}_{3}$ concentrations of 5 (a), 10 (b), 15 (c), 20 (d), 25 (e) and 30 (f) g/L and plasma-treated PPTA-PDA/Ag fibers after 10 washing cycles correspond to $(\mathrm{g}-\mathbf{1})(5-30 \mathrm{~g} / \mathrm{L})$.
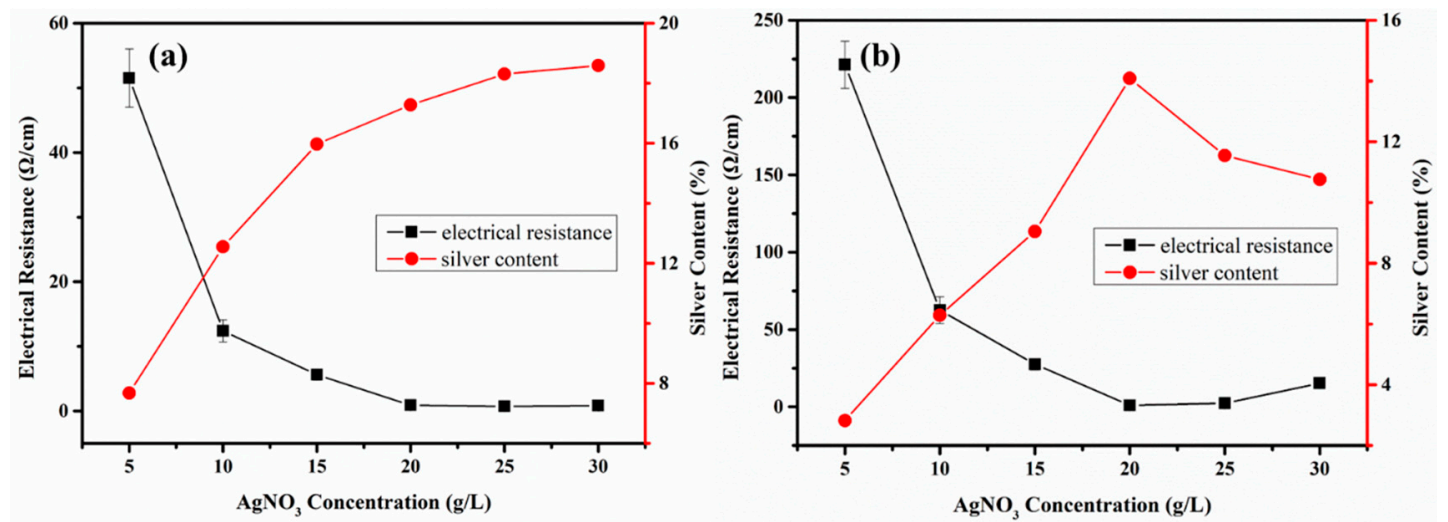

Figure 12. The relationship between the electrical resistance and silver content of plasma-treated PPTA fibers before (a) and after (b) 10 washing cycles and the $\mathrm{AgNO}_{3}$ concentration. 
As the fibers are inevitably subjected to tensile deformation in practical application, the electrical conductivity of silver-plated PPTA fibers under tensile strain was evaluated. Figure 13 shows the variation of electrical resistance under repeated stretching-releasing cycles as at a constant strain of $3 \%$ for silver-plated PPTA fibers prepared at the $\mathrm{AgNO}_{3}$ concentration of $10 \mathrm{~g} / \mathrm{L}$. It was found that in the first stretching cycle, the electrical resistance decreased from 0.91 to $0.50 \Omega / \mathrm{cm}$ as the tensile strain increased to $3 \%$. This might be because the individual fibers become tight when they are stretched and resulting in a decrease of electrical resistance [44,45]. The electrical resistance increased to the original resistance when the fiber bundles returned to the original length. In the 250th stretching cycle, the electrical resistance of the fiber bundles exhibited the same regularity as the first stretching cycle, with a slight increase in the electrical resistance. SEM observation demonstrated that the silver coating was maintained well after 250 stretching-releasing cycles. This indicates that the prepared silver-coated PPTA fibers have stable electrical conductivity under tensile deformation.

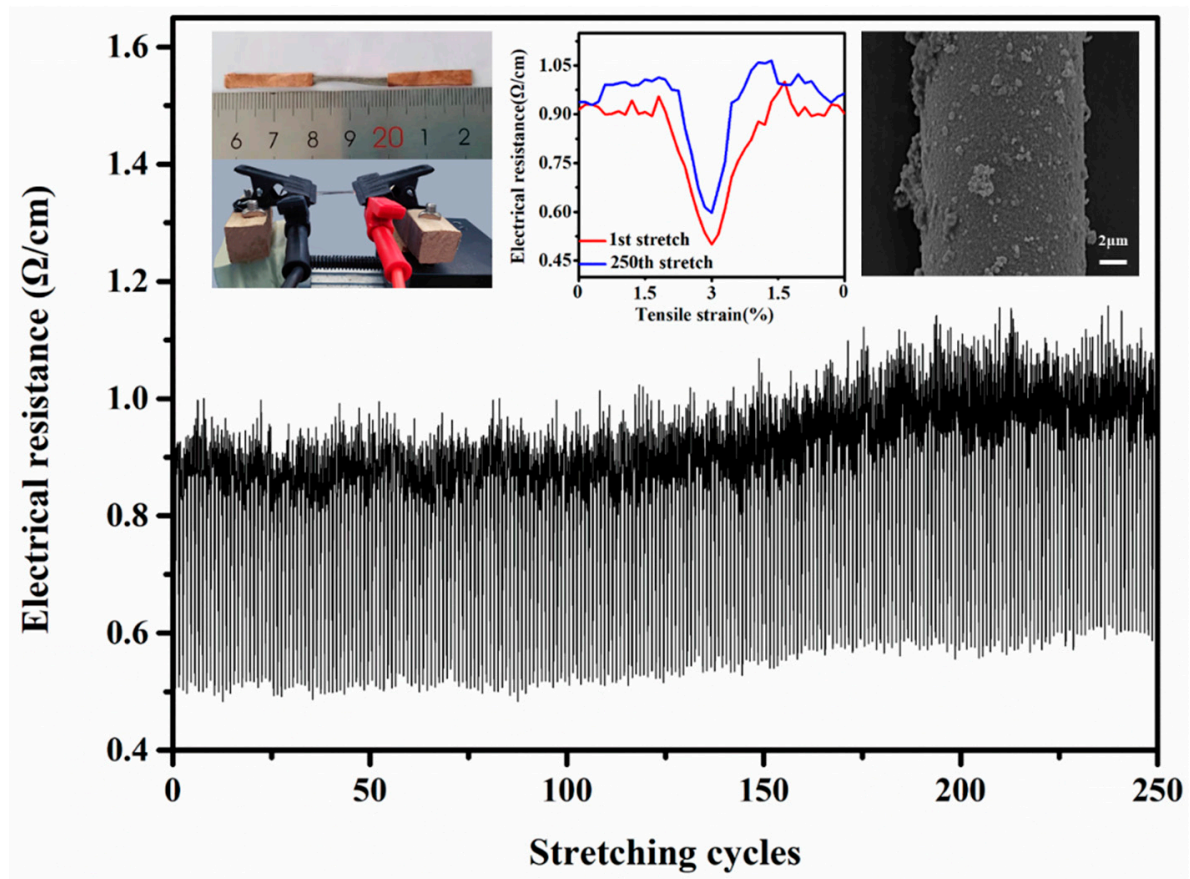

Figure 13. The relationship between the electrical resistance and tensile strain of silver-plated PPTA fibers bundles prepared at $\mathrm{AgNO}_{3}$ concentration of $10 \mathrm{~g} / \mathrm{L}$.

\section{Conclusions}

This paper describes an efficient method to prepare silver nanoparticle functionalized para-aramid fibers with excellent electrical conductivity and coating fastness. For the first time, oxygen plasma treatment together with dopamine modification was used to activate the surface of PPTA fibers prior to electroless plating. It was found that with the assistance of plasma treatment, the adsorption capacity of PPTA fibers to polydopamine and silver was greatly improved. The plasma treatment was also demonstrated to play an important role in improving the coating fastness of silver nanoparticles. At an $\mathrm{AgNO}_{3}$ concentration of $20 \mathrm{~g} / \mathrm{L}$, the electrical resistance of plasma-treated PPTA-PDA/Ag fibers prepared reached $0.89 \Omega / \mathrm{cm}$ and increased slightly to $0.94 \Omega / \mathrm{cm}$ after 10 standard washing cycles, which were obviously better than those of pristine PPTA-PDA/Ag fibers. The silver-plated PPTA fibers were also demonstrated to have stable electrical conductivity when they are subjected to repeated stretching-releasing deformation at 3\% strain. The findings of this work provide new insight into preparing silver nanoparticles coated PPTA fibers with improved conductivity and coating fastness. 
Author Contributions: All authors listed on this paper have contributed to this study. Conceptualization, Z.S. and J.M.; investigation, Z.S. and W.L.; writing—original draft preparation, Z.S.; writing-review and editing, Y.Z., S.C., S.Y. and J.M.

Funding: The authors would like to thank the financial support from the Shandong key research and development plan (special public welfare project) (2019GGX102071).

Conflicts of Interest: The authors declare no conflict of interest.

\section{References}

1. Onggar, T.; Häntzsche, E.; Hund, R.; Cherif, C. Multiple functional coating highly inert fiber surfaces of para-aramid filament yarn. Mater. Res. Express 2018, 5, 095702. [CrossRef]

2. Trexler, M.M.; Hoffman, C.; Smith, D.A.; Montalbano, T.J.; Yeager, M.P.; Trigg, D.; Nimer, S.; Calderon-Colon, X.; Peitsch, C.; Xia, Z.Y. Synthesis and mechanical properties of para-aramid nanofibers. J. Polym. Sci. Part B Polym. Phys. 2019, 57, 563-573. [CrossRef]

3. Kang, C.; Kim, S.S.; Ahn, D.; Kim, S.J.; Lee, J. Effective surface attachment Ag nanoparticles on fibers using glycidyltrimethylammonium chloride and improvement of antimicrobial properties. RSC Adv. 2017, 7, 23407-23414. [CrossRef]

4. Zhang, H.; Zou, X.; Liang, J.; Ma, X.; Tang, Z.; Sun, J. Development of electroless silver plating on para-aramid fibers and growth morphology of silver deposits. J. Appl. Polym. Sci. 2012, 124, 3363-3371. [CrossRef]

5. Jiang, L.; Zhou, Y.; Guo, Y.; Jiang, Z.; Chen, S.; Ma, J. Preparation of silver nanoparticle functionalized polyamide fibers with antimicrobial activity and electrical conductivity. J. Appl. Polym. Sci. 2019, 136, 47584. [CrossRef]

6. Guo, M.; Yi, X.; Rudd, C.; Liu, X. Preparation of highly electrical conductive carbon-fiber composites with interlaminar fracture toughness by using silver-plated interleaves. Compos. Sci. Technol. 2019, 176, 29-36. [CrossRef]

7. Liu, C.; Cheng, J.; Li, X.; Yue, P.; Gu, Z.; Ogino, K. Electroless plate of polyaniline-silver composite layer on polyester fibers. J. Polym. Eng. 2019, 39, 161-169. [CrossRef]

8. Mondin, G.; Wisser, F.M.; Leifert, A.; Mohamed-Noriega, N.; Grothe, J.; Dorfler, S.; Kaskel, S. Metal deposition by eletroless plating on polydopamine functionalized micro-and nanoparticles. J. Colloid Interface Sci. 2013, 411, 187-193. [CrossRef] [PubMed]

9. Deng, T.; Zhang, G.; Dai, F.; Zhang, F. Mild surface modification of para-aramid fiber by dilute sulfuric acid under microwave irradiation. Text. Res. J. 2017, 87, 799-806. [CrossRef]

10. Ryu, J.H.; Messersmith, P.B.; Lee, H. Polydopamine surface chemistry: A decade of discovery. ACS Appl. Mater. Interfaces 2018, 10, 7523-7540. [CrossRef]

11. Hong, S.; Na, Y.S.; Choi, S.; Song, I.T.; Kim, W.Y.; Lee, H. Non-covalent self-assembly and covalent polymerization co-contribute to polydopamine formation. Adv. Funct. Mater. 2012, 22, 4711-4717. [CrossRef]

12. Fu, Y.; Liu, L.; Zhang, L.Q.; Wang, W.C. Highly conductive one-dimensional nanofibers: Silvered electrospun silica nanofibers via poly(dopamine) functionalization. ACS Appl. Mater. Interfaces 2014, 6, 5105-5112. [CrossRef]

13. Wang, W.; Cheng, W.; Tian, M.; Zou, H.; Li, L.; Zhang, L. Preparation of PET/Ag hybrid fibers via a biomimetic surface functionalization method. Eletrochim. Acta 2012, 79, 37-45. [CrossRef]

14. Liao, Y.; Cao, B.; Wang, W.; Zhang, L.; Wu, D.; Jin, R. A facile method for preparing highly conductive and reflective surface-silvered polyimide films. Appl. Surf. Sci. 2009, 255, 8207-8212. [CrossRef]

15. Liao, Y.; Wang, Y.; Feng, X.; Wang, W.; Xu, F.; Zhang, L. Antibacterial surfaces through dopamine functionalization and silver nanoparticle immobilization. Mater. Chem. Phys. 2010, 121, 534-540. [CrossRef]

16. Liu, H.; Zhu, L.; Xue, J.; Hao, L.; Li, J.; He, Y.; Cheng, B. A novel two-step method for fabricating silver plating cotton fabrics. J. Nanomater. 2016, 2, 1-11. [CrossRef]

17. Mao, Y.; Wang, W.; Yu, D. Conductive, antibacterial, and electromagnetic shielding silver-plated cotton fabrics activated by dopamine. J. Appl. Polym. Sci. 2018, 135, 46766. [CrossRef]

18. Wang, R.; Shin, C.H.; Park, S.; Cui, L.Z.; Kim, D.; Park, J.-S.; Ryu, M. Enhanced antibacterial activity of silver-coated kapok fibers through dopamine functionalization. Water Air Soil Pollut. 2015, 226, 2241. [CrossRef] 
19. Liu, H.; Zhu, L.; He, Y.; Cheng, B. A novel method for fabricating elastic conductive polyurethane filaments by in-situ reduction of polydopamine and electroless silver plating. Mater. Des. 2017, 113, 254-263. [CrossRef]

20. Hu, W.; Zeng, Z.; Wang, Z.; Liu, C.; Wu, X.; Gu, Q. Facile fabrication of conductive ultrahigh molecular weight polyethylene fibers via mussel-inspired deposition. J. Appl. Polym. Sci. 2013, 128, 1030-1035. [CrossRef]

21. Shen, L.; Yu, L.; Wang, M.; Wang, X.; Zhu, M.; Hsiao, B.S. Green fabrication of Ag coated polyacrylonitrile nanofibrous composite membrane with high catalytic efficiency. J. Nanosci. Nanotechnol. 2015, 15, 5004-5012. [CrossRef]

22. Mao, Y.; Zhu, M.F.; Wang, W.; Yu, D. Well-defined silver conductive pattern fabricated on polyester fabric by screen printing a dopamine surface modifier followed by electroless plating. Soft Matter 2018, 14, 1260-1269. [CrossRef]

23. Liu, C.; Li, X.; Li, X.; Xu, T.; Song, C.; Ogino, K.; Gu, Z. Preparation of conductive polyester fibers using continuous two-step plating silver. Materials 2018, 11, 2033. [CrossRef]

24. Ma, S.Y.; Liu, L.; Bromberg, V.; Singler, T.J. Fabrication of highly electrically conducting fine patterns via substrate-independent inkjet printing of mussel-inspired organic nano-material. J. Mater. Chem. C 2014, 2, 3885-3889. [CrossRef]

25. Xu, C.H.; Tian, M.; Liu, L.; Zou, H.; Zhang, L.; Wang, W. Fabrication and properties of silverized glass fiber by dopamine functionalization and electroless plating. J. Electrochem. Soc. 2012, 159, D217-D224. [CrossRef]

26. Wang, W.; Li, R.; Tian, M.; Liu, L.; Zou, H.; Zhao, X.; Zhang, L. Surface silverized meta-aramid fibers prepared by bio-inspired poly(dopamine) functionalization. ACS Appl. Mater. Interfaces 2013, 5, 2062-2069. [CrossRef]

27. Yu, D.; Mu, S.; Liu, L.; Wang, W. Preparation of electroless silver plating on aramid fiber with good conductivity and adhesion strength. Colloids Surf. A Physicochem. Eng. Asp. 2015, 483, 53-59. [CrossRef]

28. Lin, F.; Li, W.; Tang, Y.; Shao, H.; Su, C.; Jiang, J.; Chen, N. High-performance polyimide filaments and composites improved by $\mathrm{O}_{2}$ plasma treatment. Polymers 2018, 10, 695. [CrossRef]

29. Su, M.; Gu, A.J.; Liang, G.Z.; Yuan, L. The effect of oxygen-plasma treatment on Kevlar fibers and the properties of Kevlar fibers/bismaleimide composites. Appl. Surf. Sci. 2011, 257, 3158-3167. [CrossRef]

30. Wang, J.; Chen, P.; Li, H.; Zhang, C.; Sun, B.; Zhang, X. The analysis of Armos fibers reinforced poly (phthalazinone ether sulfone ketone) composite surfaces after oxygen plasma treatment. Surf. Coat. Technol. 2008, 202, 4986-4991. [CrossRef]

31. Wang, J.; Chen, P.; Li, H.; Li, W.; Wang, B.; Zhang, C.; Ren, N. Surface characteristic of poly (p-phenylene terephthalamide) fibers with oxygen plasma treatment. Surf. Interface Anal. 2008, 40, 1299-1303. [CrossRef]

32. Sun, X.; Bu, J.; Liu, W.; Niu, H.; Qi, S.; Tian, G.; Wu, D. Surface modification of polyimide fibers by oxygen plasma treatment and interfacial adhesion behavior of a polyimide fiber/epoxy composite. Sci. Eng. Compos. Mater. 2017, 24, 477-484. [CrossRef]

33. Sa, R.; Yan, Y.; Wei, Z.; Zhang, L.; Wang, W.; Tian, M. Surface modification of aramid fibers by bio-inspired poly(dopamine) and epoxy functionalized silane grafting. ACS Appl. Mater. Interfaces 2014, 6, 21730-21738. [CrossRef]

34. Chai, D.; Xie, Z.; Wang, Y.; Liu, L.; Yum, Y.J. Molecular dynamics investigation of the adhesion mechanism acting between dopamine and the surface of dopamine-processed aramid fibers. ACS Appl. Mater. Interfaces 2014, 6, 17974-17984. [CrossRef]

35. Knorr, D.B.; Tran, N.T.; Gaskell, K.J.; Orlicki, J.A.; Woicik, J.C.; Jaye, C.; Fischer, D.A.; Lenhart, J.L. Synthesis and characterization of aminopropyltriethoxysilane-polydopamine coatings. Langmuir 2016, 32, 4370-4381. [CrossRef]

36. Nimisha, S.; Nayak, J.; Khushbu, P.; Sahoo, S.K.; Rajender, K. Electrochemical impedance spectroscopy reveals new mechanism based on competitive binding between Tris and protein on conductive biomimetic polydopamine surface. Phys. Chem. Chem. Phys. 2018, 20, 25812-25821.

37. Ball, V.; Frari, D.D.; Toniazzo, V.; Rush, D. Kinetics of polydopamine film deposition as a function of $\mathrm{pH}$ and dopamine concentration: Insights in the polydopamine deposition mechanism. J. Colloid Interface Sci. 2012, 386, 366-372. [CrossRef]

38. Vecchia, N.F.D.; Luchini, A.; Napolitano, A.; D’Errico, G.; Vitiello, G.; Szekely, N.; d'Ischia, M.; Paduano, L. Tris buffer modulates polydopamine growth, aggregation, and paramagnetic properties. Langmuir 2014, 30, 9811-9818. [CrossRef]

39. GB/T 3921-2008, Textiles-Tests for Colour Fastness-Colour Fastness to Washing with Soap or Soap and Soda; Standards Press of China: Beijing, China, 2008. 
40. Li, X.; Shan, H.; Cao, M.; Li, B. Mussel-inspired modification of PTFE membranes in a miscible THF-Tris buffer mixture for oil-in-water emulsions separation. J. Membr. Sci. 2018, 555, 237-249. [CrossRef]

41. Li, S.; Han, K.; Rong, H.; Li, X.; Yu, M. Surface modification of aramid fibers via ammonia-plasma treatment. J. Appl. Polym. Sci. 2014, 131, 40250. [CrossRef]

42. Xi, M.; Li, Y.; Shang, S.; Li, D.; Yin, Y.; Dai, X. Surface modification of aramid fiber by air DBD plasma at atmospheric pressure with continuous on-line processing. Surf. Coat. Technol. 2008, 202, 6029-6033. [CrossRef]

43. Hwang, Y.J.; Qiu, Y.; Zhang, C.; Jarrard, B.; Stedeford, R.; Tsai, J.; Park, Y.C.; McCord, M. Effects of atmospheric pressure helium/air plasma treatment on adhesion and mechanical properties of aramid fibers. J. Adhes. Sci. Technol. 2003, 17, 847-860. [CrossRef]

44. Ma, Z.; Xu, R.; Wang, W.; Yu, D. A wearable, anti-bacterial strain sensor prepared by silver plated cotton/spandex blended fabric for human motion monitoring. Colloids Surf. A Physicochem. Eng. Asp. 2019, 123918. [CrossRef]

45. Wang, Z.H.; Wang, W.; Yu, D. Pressure responsive PET fabrics via constructing conductive wrinkles at room temperature. Chem. Eng. J. 2017, 330, 146-156. [CrossRef]

(C) 2019 by the authors. Licensee MDPI, Basel, Switzerland. This article is an open access article distributed under the terms and conditions of the Creative Commons Attribution (CC BY) license (http://creativecommons.org/licenses/by/4.0/). 